\title{
Bir Kamu Kurumunda Bulunan Asbest Uygulama Merkezi ve SEM Laboratuvarında L Tipi Matris Yöntemi ile Risk Değerlendirmesi
}

\author{
Risk Assessment by L Type Matrix Method in Asbestos Application Center and SEM \\ Laboratory in a Public Institution
}

Şehmus ÜNVERDi (DD , Saliha ÇETINYOKUŞ

\begin{abstract}
ÖZET
İș sağlığı ve güvenliği büyüklük, tehlike sınıfı gözetilmeksizin tüm işyerleri için önemli bir kavramdır. Düşük risk seviyesine sahip bir risk çok ciddi can, mal ve çevre kayıplarına yol açabilmektedir. İşin sağlıklı ve güvenli bir ortamda yerine getirilmesi, ancak tüm risk seviyeleri için ilgili kontrol ve tedbirlerin alınması ve takibi ile gerçekleştirilebilir. Bu çalışmada, tehlikeli sınıfta yer almayan bir kamu kurumunun iki ayrı bölümünde risk analizi çalışması yürütülerek olası tüm risklerin belirlenmesi ve risk azaltıcı faaliyetlerin önerilmesi amaçlanmıştır. Risk analizi, kolay ve etkin sonuçlar üreten ve seçilen işyeri için uygun olan L-tipi risk matrisi yöntemi ile gerçekleştirilmiştir. Öncelikle, işyerinde risk analizi yapılacak bölümler ve faaliyetler incelenmiş ve tehlike kaynakları belirlenmiștir. Ardından her bir tehlike kaynağı ilgili tehlike mekanizması ile ilişkilendirilerek riskler listelenmiştir. Seçilen risk analizi yöntemi ile olasılık, şiddet değerleri üzerinden risk skorları ve risk seviyeleri elde edilmiştir. Çalışma sonucunda, işyerindeki iki bölüm için 4'ü kabul edilemez risk(kırmızı), 8'i dikkate değer risk (sarı) ve 1'i kabul edilebilir risk (yeşil) olmak üzere toplam 13 risk tespit edilmiştir. Belirlenen risk sayısı az olmasına rağmen sadece risklerin\%7,6' sının kabul edilir seviyede bulunması, ilgili bölümlerin riskli olduğunu göstermiștir. Özellikle, kabul edilemez (kırmızı) risklerin belirlendiği kimyasal tehlike kaynaklarına yönelik acil önlemler alınması gereği gösterilmiştir.

Anahtar Kelimeler: İș sağlığı ve güvenliği, risk analizi, risk değerlendirmesi, L-tipi risk matris yöntemi .

\section{ABSTRACT}

Occupational health and safety is an important concept for all workplaces regardless of size and hazard class. A risk with a low risk level can lead to serious loss of life, property and environment. Carrying out the work in a healthy and safe environment can only be achieved by taking and checking the relevant controls and measures for all risk levels. In this study, it was aimed to determine all possible risks and suggest risk-reducing activities by conducting a risk analysis study in two separate sections of a public institution that is not classified as dangerous. Risk analysis was carried out using the L-type risk matrix method, which produces easy and effective results and is suitable for the chosen workplace. First of all, the departments and activities to be risk analyzed in the workplace were examined and the sources of danger were determined. Then, the risks were listed by associating each hazard source with the relevant hazard mechanism. With the selected risk analysis method, risk scores and risk levels were obtained on the basis of probability and severity values. As a result of the study, a total of 13 risks were identified for two sections in the workplace, of which 4 were unacceptable risks (red), 8 were significant risks (yellow) and 1 was acceptable risk (green). Although the number of risks identified was small, only $7.6 \%$ of the risks were at an acceptable level, showing that the relevant departments were risky. In particular, the need to take urgent measures for chemical hazard sources where unacceptable (red) risks were identified.

Keywords: Occupational health and safety, risk analysis, risk assessment, L-type matrix method.
\end{abstract}

Şehmus ÜNVERDi | sehmusunverdi06@gmail.com

Gazi Üniversitesi, Fen Bilimleri Enstitüsü, Kazaların Çevresel ve Teknik Araşttrması, Ankara, Türkiye

Gazi University, Graduate School of Natural and Applied Sciences, Environmetal and Technical Research on Accidents, Ankara, Turkey

Saliha ÇETINYOKUŞ | salihakilicarslan@gazi.edu.tr | Sorumlu Yazar/Corresponding Author Gazi Üniversitesi, Mühendislik Fakültesi, Kimya Mühendisliği, Ankara, Türkiye Gazi University, Engineering Faculty, Chemical Engineering, Ankara, Turkey 


\section{GİRIŞ}

6331 sayılı İş Sağlığı ve Güvenliği (İSG) Kanunu’nu istisnalar hariç tüm çalışanlar ile faaliyet konularına bakılmaksızın (kamu ve özel) tüm işyerlerini kapsar ve tüm paydaşlarca genelde sağlık ve güvenliğe, özelde ise risk analizi kavramına olan ilgiyi artırmaktadır [1]. Ayrıca, 18 Haziran 2013' de yayınlanan “Işs Yerlerinde Acil Durumlar Hakkında Yönetmelik” de işyeri acil durum planının oluşturulması ve bu plan ile önleme, koruma, tahliye, yangınla mücadele, ilk yardım vb. konularda yapılması gereken çalısmalar, bunların güvenli olarak yönetilmesi ve görevlendirilecek çalışanların belirlenmesi risk analizine dayanmaktadır[2].

Risk analizinin temel amacı işyerindeki iş kazası ve meslek hastalığına sebep olabilecek riskleri tespit etmek, gerekli düzeltici ve önleyici tedbirleri almaktır. Her bir tehlike ayrı ayrı ele alınarak bunların yol açacağı riskler olasılık ve şiddet üzerinden belirlenir. Risk analizi kalitatif veya kantitatif yöntemler kullanılarak geçekleştirilebilir. Dünya ve özellikle AB uygulamalarına bakıldığında; kurumsal risk yönetiminde veya teknik açıdan sağlık ve güvenlik risklerinin değerlendirilmesinde genellikle matris yönteminin tercih edildiği görülmektedir [3].

L-tipi risk matrisi ( 5 x 5 Matris diyagramı) basit, uzmanlık gerektirmeyen, hızlı uygulanması yönleri ile avantajlı bir kalitatif risk analiz metodudur. Literatürde bu risk analiz yönteminin farklı sektörlerde kullanımına yönelik çalışmalar yer almaktadır. Bir kamu üniversitesinin gıda mühendisliği laboratuvarlarında toplam 6 adet uygulama ve kontrol listeleri kullanılarak risk analizi gerçekleştirilmiştir. İlgili laboratuvarlarda 6 kabul edilemez risk, 24 yüksek risk, 19 orta risk, 3 düşük risk olmak üzere toplam 52 risk tespit edilmiştir. Laboratuvarlar için ortalama risk skoru 15 (yüksek riskli) olarak belirlenmiştir [4]. 200 kilogram alın işleme kapasitesi(yıllık ortalama) ve 50 çalışana sahip bir mücevherat fabrikasında risk analizi gerçekleştirilmiş; ana üretim hatlarında yüksek risk skorları elde edilmiştir. Ham madde işleme süresince yüksek sıcaklık, basınçlı makineler ve kimyasallar önemli tehlikeler olarak açıklanmıştır. Fabrikanın ofis ve atölye bölümlerinde ise dikkate değer risk ve kabul edilebilir risk seviyeleri elde edilmiştir [5]. Eskişehir'de faaliyet gösteren bir firmanın açık ocak işletmesindeki madencilik faaliyetleri için risk analizi gerçekleş̧irilmiştir. Risk skoru yüksek çıkan bölümler sırasıyla maden sahasında herhangi bir taş düşmesi, devrilen ya da yukarıdan düşen cisimler tehlikelerini kapsayan yüksekten düşürme/ düşme 20-25, patlama, 15-25, patlayıcı madde 15-25 ve üretim esnasındaki toz 14 olarak belirlenmiştir [6]. Metal sektöründe gerçekleştirilen bir başka çalş̧mada ise 10 adet yüksek risk ve 17 adet orta risk tespit edilmiştir. Tespit edilen bu risklerin tamamının alınacak önlemler ile düşük risk seviyesine indirilebileceği gösterilmiştir [7]. Bir tekstil işletmesinde gerçekleştirilen risk değerlendirme uygulamasında 24 adet kabul edilemez risk ve 6 adet dikkate değer tespit edilmiştir. Bu çalışmada $5 \times 5$ matris yöntemiyle yapılan değerlendirmenin diğer yöntemlere göre daha kısa sürede tamamlandığı vurgulanmıştır [8]. 5x5 Matris, Fine Kinney ve FMEA yöntemleri kullanılarak ilaç lojistik sektöründe risk analizi yapılmış, $5 \times 5$ Matris metodunun daha genel ve ön hazırlık oluşturabilecek nitelikte kullanılabilir olduğu belirtilmiştir [9]. Şimşek ve arkadaşları tarafından makineler özelinde $5 \times 5$ matris yöntemi kullanılmış ve kabul edilemez risk seviyesinde tespit edilen risklerin çoğunun sensör kullanımı ile \%75 oranında elimine edilebileceği açıklamıştır [10]. Oto tamirhanelerindeki mekanik çalışmalar için gerçekleştirilen risk analizi çalışmasında \%50 kabul edilemez risk, \%25 dikkate değer risk ve \%25 oranında ise kabul edilebilir risk olduğu belirlenmiştir. Risklerin büyük çoğunluğunun kimyasal kaynaklı olduğu ve maruziyet sonucunda da ciltte tahrişler, yaralanmalar, yanma 
ve parlama risklerinin oldu tespit edilmiştir [11]. Kimyasal araştırma laboratuvarında gerçekleștirilen risk değerlendirmesi çalışmasında 35 adet risk tespit edilmiş ve bunların 10 tanesinin kabul edilemez risk, 23 tanesinin dikkate değer risk ve 2 tanesinin de kabul edilebilir risk seviyesinde olduğu açıklanmıştır [12].

Bu çalışmada, L-tipi matris yöntemi kullanılarak bir kamu kurumunda risk analizi yapılmıştır. Risk analizi kurum içerisinde bulunan iki ayrı bölüm ve bunlara ait tüm ekipman ve makineleri kapsamaktadır.

\section{MATERYAL VE METOT}

\section{A. Risk Analiz Yöntemi}

Çalışmada L-tipi matris yöntemi kullanılarak risk analizi yapılmıştır. Matris yöntemi, profesyonel yargıyı öne çıkaran (bazen sayısal veri tabanı da kullanılması nedeniyle yarı nitel de denebilen) nitel bir yöntemdir. Bu yöntem çalışanların ve yöneticilerin risk kavramını algılamasında etkin bir rol oynamaktadır. Risk analizi yönteminin seçilmesinde ülkelerin ve özellikle $A B$ uygulamasının bu deneyimi esas teşkil etmektedir. L-tipi risk matrisi, sebep-sonuç ilişkilerinin değerlendirilmesinde özellikle kullanılmaktadır. Bu yöntem kolay anlaşılabilir ve uygulanabilir olması nedeniyle kamu binaları ve benzeri yerler için daha uygundur. Ayrıca, bu yöntem derhal önlem alınması gerekli olan tehlikelerin tespitinin yapılabilmesi için kullanılmaktadır. Yöntemde bir tehlikenin neden olabileceği aksiliğin gerçekleşme olasılığg ile gerçekleşmesi durumunda sonucunun (şiddetinin) derecelendirilmesi yapılır. Olasılık ve şiddet çarpımından risk skoru elde edilir.

\section{Risk Skoru= Olasılık x Şiddet}

L-tipi risk matrisi risk skoru, şiddet tablosu (Tablo 1) ve olasılığı tanımlayan tablo (Tablo 2) üzerinden hesaplanır. Örneğin; bir ofiste tehlike unsuru olarak hasarlı bir priz tespit edilmişse ve bu tehlikenin riskinin de elektrik çarpması olduğu düşünüldüğünde, çarpılma sonucunun yaralanma veya ölüm olup olmayacağını değerlendirmek gerekmektedir. Bir sonraki aşamada ise bu sonucun olasıllğının (hangi sıklıkta olabileceği) değerlendirilmesi gerekmektedir. Hasarlı priz kullanımı ile çalışanın elektrik çarpılması ciddi yaralanma ya da ölümle sonuçlanabilir

Tablo 1. L-tipi Matris Şiddet Tablosu

\begin{tabular}{lll}
\hline \multicolumn{1}{c}{ ŞIDDET } & \multicolumn{1}{c}{ DERECELENDiRME } \\
\hline 1 ÇOK HAFiF & İş saati kaybı yok, ilkyardım gerektiren \\
2 HAFiF & İş günü kaybı yok, ilk yardım gerektiren \\
3 ORTA & Hafif yaralanma, tedavi gerekir \\
4 CiDDi & Ölüm, Ciddi yaralanma, meslek hastalığı \\
5 & ÇOK CiDDi & Birden çok ölüm, sürekli iş göremezlik \\
\hline
\end{tabular}

Tablo 1 incelendiğinde, elektrik çarpmasının ciddi yaralanma veya ölüm ile sonuçlanacağı öngörüsü ile şiddeti 4 kabul edebilir. Olasılığı hesaplamak için ise bu tehlikeli durumun riske dönüşmesi ihtimalini göz önüne alınması gerekir.

Tablo 2. L-tipi Matris Olasılık Tablosu

\begin{tabular}{ll}
\hline OLASILIK & $\begin{array}{l}\text { ORTAYA ÇIKMA OLASILIĞI/FREKANS IçiN } \\
\text { DERECELENDiRME BASAMAKLARI }\end{array}$ \\
\hline 1 çOK KÜÇÜK & Uzak olası (hemen hemen hiç) \\
2 KÜçÜK & Az Olası (yılda bir kez) \\
3 ORTA & Olası (yılda birkaç kez) \\
4 YÜKSEK & Sık Sık (ayda bir veya birkaç kez) \\
5 çOK YÜKSEK & Çok Sık (haftada bir veya her gün - sürekli) \\
\hline
\end{tabular}

Hasarlı prizin sürekli olarak bulunması ve çalışanın devamlı prizi kullanması, çarpılmanın her an olabileceğini göstermektedir. Tablo 2’ ye göre bu tehlike için olasılık “4” kabul edilebilir. Şiddeti ve olasılığı 4 kabul edilen hasarlı priz tehlikesi için risk skoru 16 olarak hesaplanır. L-tipi risk matrisinde (Tablo 3) bu değer yerleştirildiğinde riskin kırmızı bölgede ve "yüksek risk" derecesinde olduğu belirlenir. Risk skoru eylem tablosu(Tablo 4) dikkate alındığında bu risk ile ilgili derhal düzeltici ve önleyici çalışma ya- 
pılması gerekmektedir.

Tablo 3. L-tipi Risk Matrisi

\begin{tabular}{|c|c|c|c|c|c|}
\hline & \multicolumn{5}{|c|}{ ŞIDDET } \\
\hline OLASILIK & $\begin{array}{c}\text { ÇOK ciDdi } \\
5\end{array}$ & $\begin{array}{c}\text { cidoi } \\
4\end{array}$ & $\begin{array}{l}\text { ORTA } \\
3\end{array}$ & $\begin{array}{c}\text { HAFiF } \\
2\end{array}$ & ÇOK HAFiF \\
\hline $\begin{array}{c}\text { CCOK } \\
\text { YÜKSEK } \\
5\end{array}$ & $\begin{array}{c}\text { YÜKSEK } \\
25\end{array}$ & $\begin{array}{c}\text { YÜKSEK } \\
20\end{array}$ & $\begin{array}{l}\text { YÜKSEK } \\
15\end{array}$ & $\begin{array}{l}\text { ORTA } \\
10\end{array}$ & $\begin{array}{l}\text { DUş̧üK } \\
5\end{array}$ \\
\hline $\begin{array}{l}\text { YÜKSEK } \\
4\end{array}$ & $\begin{array}{l}\text { YÜKSEK } \\
20\end{array}$ & $\begin{array}{c}\text { YUUKSEK } \\
16\end{array}$ & $\begin{array}{l}\text { ORTA } \\
12\end{array}$ & $\begin{array}{c}\text { ORTA } \\
8\end{array}$ & $\begin{array}{c}\text { DÜşüK } \\
4\end{array}$ \\
\hline $\begin{array}{c}\text { ORTA } \\
{ }_{3}\end{array}$ & $\begin{array}{l}\text { ORTA } \\
15\end{array}$ & $\begin{array}{r}\text { ORTA } \\
12\end{array}$ & $\begin{array}{c}\text { ORTA } \\
9\end{array}$ & $\begin{array}{c}\text { DUşü } \\
6\end{array}$ & DUŞÜK \\
\hline $\begin{array}{c}\text { KÜçüKK } \\
2\end{array}$ & $\begin{array}{l}\text { ORTA } \\
10\end{array}$ & $\begin{array}{l}\text { ORTA } \\
8\end{array}$ & $\begin{array}{c}\text { DŪşuK } \\
6\end{array}$ & DŪşüK & $\begin{array}{l}\text { DUşüK } \\
2\end{array}$ \\
\hline $\begin{array}{c}\text { coK } \\
\text { KỤ̧̂UK } \\
1\end{array}$ & $\begin{array}{l}\text { DUŞÜK } \\
5\end{array}$ & DUŞ̧UK & DUŞUKK & 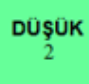 & $\begin{array}{c}\text { DUŞÜK } \\
1\end{array}$ \\
\hline
\end{tabular}

Tablo 4. Risk Skoru Eylem Tablosu

\begin{tabular}{ll}
\hline RISK SKORU & EYLEM \\
\hline \multirow{2}{*}{$15,16,20,25$} & $\begin{array}{l}\text { Yüksek(Kabul Edilemez) Risk } \\
\text { Bu risklerle ilgili hemen düzeltici- önleyici çalışma } \\
\text { yapılmalıdır }\end{array}$ \\
\hline \multirow{2}{*}{$8,9,10,12$} & $\begin{array}{l}\text { Orta(Dikkate Değer) Risk } \\
\text { Bu risklere mümkün olduğu kadar çabuk müdahale } \\
\text { edilmelidir } \\
\text { (6 ay içerisinde yönetimin onayı ile) }\end{array}$ \\
\hline \multirow{2}{*}{$1,2,3,4,5,6$} & $\begin{array}{l}\text { Düşük(Kabul Edilebilir )Risk } \\
\text { Acil tedbir gerektirmeyebilir (1 yıl içerisinde veya } \\
\text { daha fazla yönetimin onayı ile) }\end{array}$ \\
\hline
\end{tabular}

\section{B. Uygulama}

Risk analizi bir kamu kurumunda bulunan asbest uygulama merkezi ve sem laboratuvarı olmak üzere iki ayrı bölümde, ilgili tüm ekipman ve makineler dikkate alınarak gerçekleştirilmiştir. Asbest uygulama merkezi ve sem laboratuvarı asbest söküm uzmanlığı eğitimlerinde kullanılmaktadır. Asbest uygulama merkezinde sunumların gerçekleştirileceği alan, uygulama alanı, cihaz ve ekipman ile asbest numunelerinin örnekleri yer almaktadır. SEM laboratuvarında ise taramalı elektron mikroskobu ve analiz bilgisayarı, azot ve argon gaz tüpleri ile sıvı azot tüpü yer almaktadır. Risk analizi yapılırken sırasıyla aşağıdaki adımlar uygulanmışır:

1) Tehlikelerin belirlenmesi

2) Risklerin belirlenmesi

3) Risklerin olasılık ve şiddet değerlerinin belirlenmesi

4) Risk değerlerinin elde edilmesi

5) Alınacak önlemlerin belirlenmesi (Risk kontrol önlemleri)

6) Risklerin derecelendirilmesi

7) Risk kontrol önlemlerinin uygulanması

8) Uygulanan sistemin denetimi, izlenmesi ve gözden geçirilmesi

$\mathrm{Bu}$ adımlar gerçekleştirilirken aşağıda belirtilen bilgi ve dokümanlar dikkate alınmışıı:

- İş akış şemaları (gerekliyse),

- İssyeri yerleşim planları (gerekliyse),

- İssyeri mesai saatleri,

- İşyeri çalışan sayısı (kadın/erkek/genç/engelli),

- İşsüreçlerini anlatan dokümanlar,

- Makina ve ekipman listesi,

- Kimyasal maddelerin listesi, malzeme güvenlik bilgi formları,

- Bakım-kullanım ve İSG talimatları,

- İşyeri ortam ölçümleri,

- Periyodik test ve kontroller,

- Son 5 yıl içerisinde meydana gelen iş kazaları ve meslek hastalıkları, varsa ramak kala kazalar,

- Varsa daha önceden yapılan risk analizi,

- Acil durum planlarr,

- Yangın eğitim ve tatbikatları,

- Altyüklenici, taşeron ve tedarikçi faaliyetleri ile bu taraflarla yapıllan sözleşmeler,

- İSG kurulu çalışmaları,

- Yıllık eğitim planı vb.

Risk analizinin planlanması kapsamında aşă̆ıdaki adımlar takip edilmiştir:

I. Risk analizi yapılacak alan ve faaliyetler belirlenmiştir,

II. Uygulanacak risk analizi metodolojisi belirlenmiştir, 


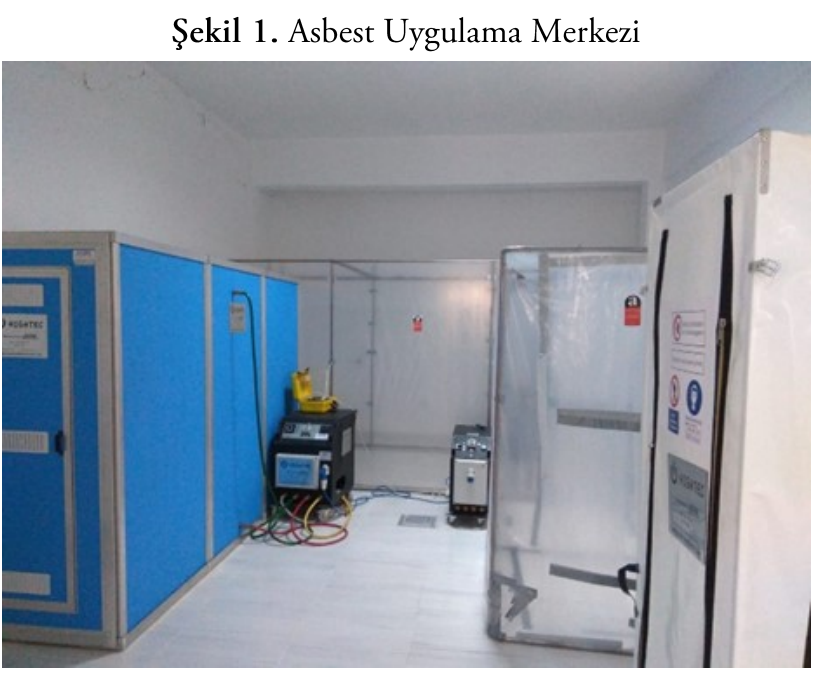

Şekil 2. SEM Cihazı

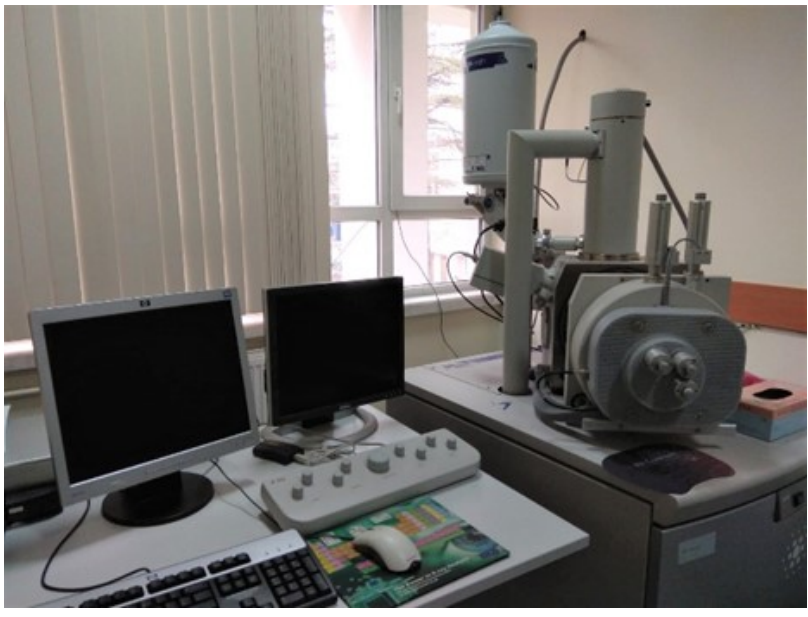

Şekil 3. SEM Laboratuvarı Argon ve Azot Tüpleri (1), Sıv1 Azot Tüpü (2)

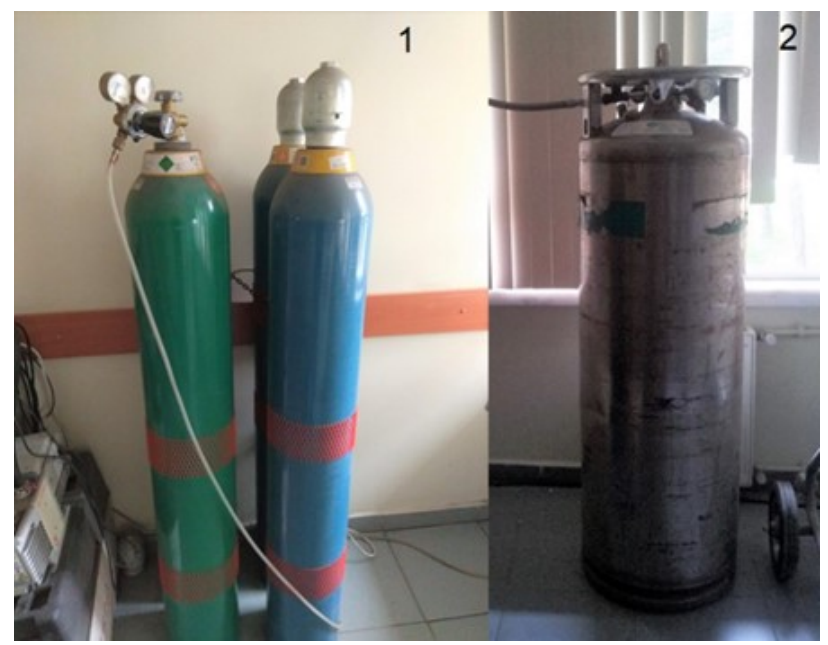

III. Belirlenen alan ve faaliyetlere göre seçilen metodoloji de göz önünde bulundurularak tehlike kaynakları belirlenmiştir,

IV. Risk analizi yapılacak alanlarda, o alanlardaki çalışma şartları ve işs süreçleri hakkında bilgi alınabilecek ilgililerle temasa geçilmiştir,

V. Yerinde yapılacak risk analizi incelemeleri için takvim oluşturulmuştur.

Planlamanın ardından risk analizi yapılacak alanlar incelenmiştir. (Şekil 1-3) Asbest uygulama merkezinde iki İş Sağlığı ve Güvenliği Uzmanı (Kimya Mühendisi, Çevre Mühendisi) ve bir Kimya Mühendisi olmak üzere üç çalışan ile görüşülmüştür. SEM laboratuvarında ise bir Kimyager ve bir Kimya Mühendisi olmak üzere iki çalışan ile görüşme gerçekleştirilmiştir. İncelemelerin ardından L-tipi risk matrisi metodu ile risk analizi yapılmış ve riskli alanlar belirlenerek derecelendirilmiştir.

\section{BULGULAR VE TARTIŞMA}

L tipi matris metodu uygulanarak risk analizi çalışsması gerçekleştirilmiş ve tehlikelerin, tehlikelerden kaynaklanan risklerin ve çözüm önerilerinin bulunduğu risk analizi tablosu (Tablo 5 ve Tablo 6) hazırlanmıştır. Risk analizi yapılan iki bölümde 4'ü kabul edilemez risk (kırmızı), 8’i dikkate değer risk(sarı) ve 1'i kabul edilebilir risk (yeşil) olmak üzere toplam 13 risk tespit edilmiştir. Kabul edilemez ve derhal müdahale edilmesi gereken risklerin toplam riske oranı $\% 31$ olarak belirlenmiştir.

Belirlenen 13 riskin kamu kurumundaki ilgili bölümler için dağlımı ise Tablo 7'de verilmiştir. Tablo 7'den kamu kurumunda incelenen birinci bölüm olan asbest uygulama merkezinde 7, ikinci bölüm olan sem laboratuvarında ise 6 risk tespit edilmiştir. İncelenen sem laboratuvarında kabul edilemez risklerin oranı \%50 olarak belirlenmiştir. Risk değerlendirmesi yapıllıken sadece risk skoru değil ilgili bölümler için kabul edilemez risk oranlarının da dikkate alınması gerekmektedir. 


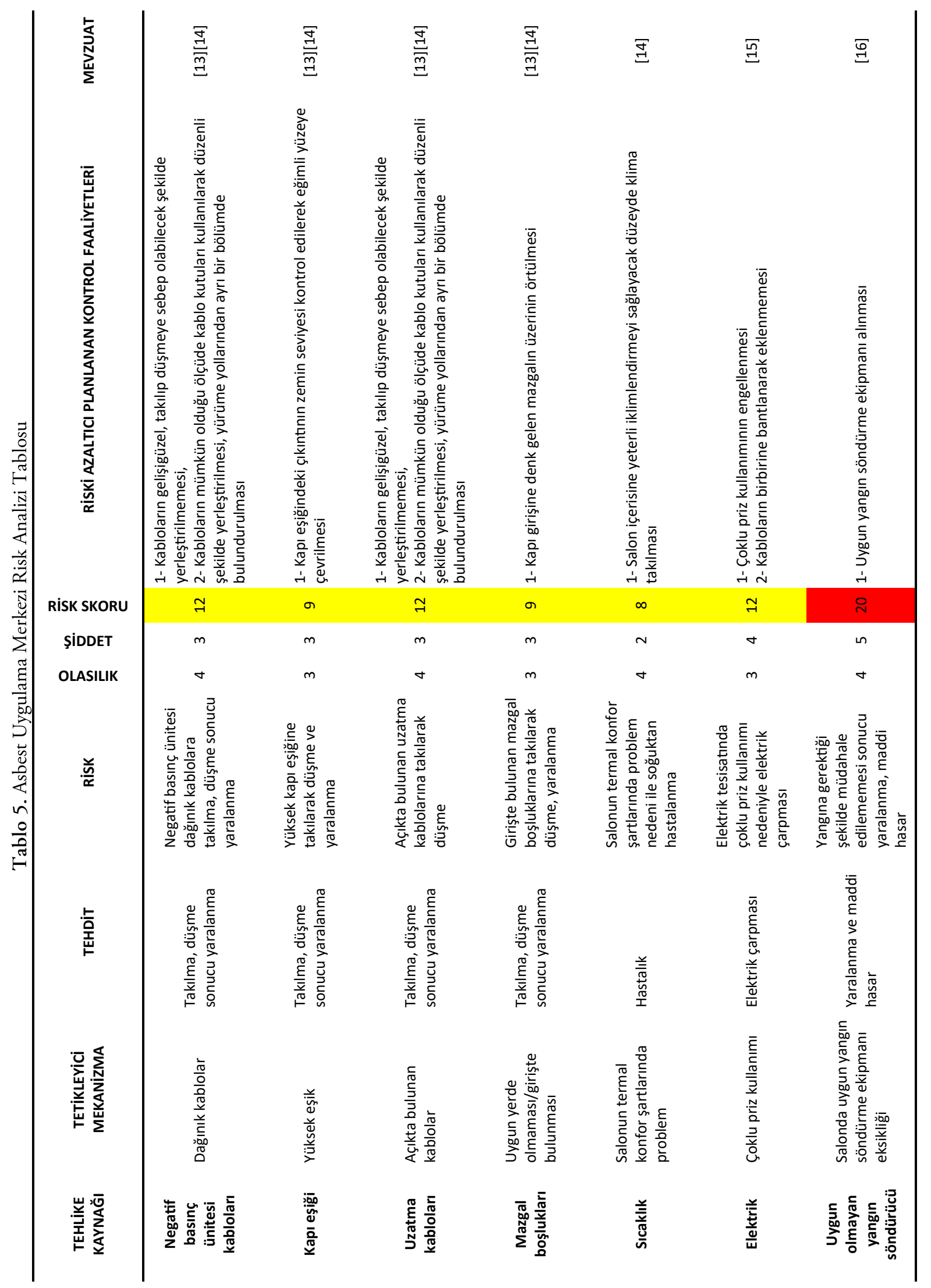


Karaelmas İ̧ Să̆lığı ve Güvenliği Dergisi, Cilt 5, Sayı 2, 2021, ss. 99-107

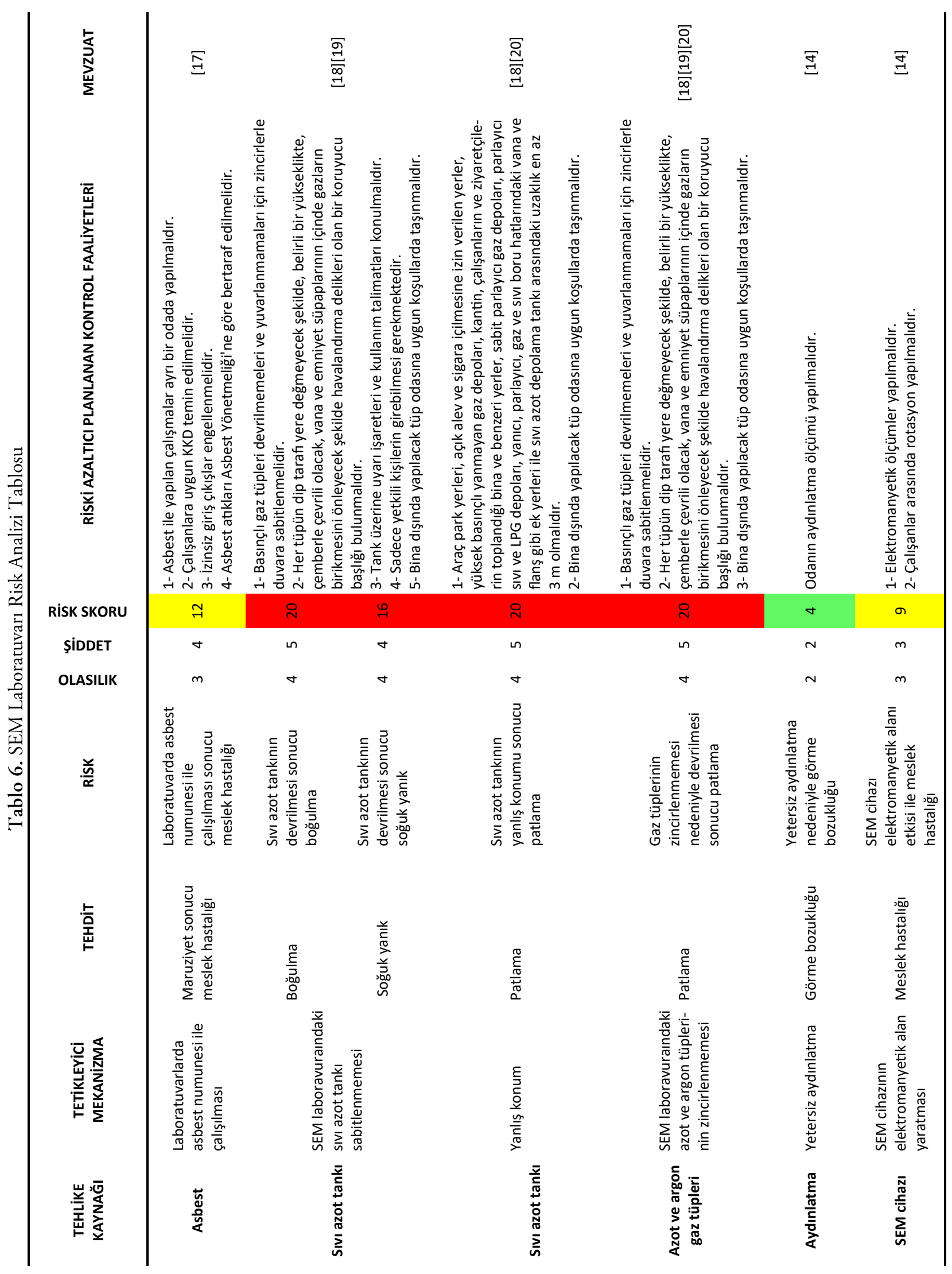


Tablo 7. İncelenen Bölümlere Göre Risk Seviyeleri ve Sayıları

\begin{tabular}{lcccc}
\hline Bölüm & Kabul Edilemez Risk Sayısı & Dikkate Değer Risk Sayısı & Kabul Edilebilir Risk Sayısı & Toplam Risk Sayısı \\
\hline Asbest Uygulama Merkezi & 1 & 6 & 0 & $\mathbf{7}$ \\
SEM Laboratuvarı & 3 & 2 & 1 & $\mathbf{6}$ \\
\hline TOPLAM & 4 & 8 & 1 & 13 \\
\hline
\end{tabular}

Tablo 8. Tehlike Kaynaklarına Göre Risk Dağılımı

\begin{tabular}{lccc}
\hline \multicolumn{1}{c}{ TEHLikE KAYNAĞı } & $\begin{array}{c}\text { Kabul Edilemez } \\
\text { Risk Sayısı }\end{array}$ & $\begin{array}{c}\text { Dikkate Değer } \\
\text { Risk Sayısı }\end{array}$ & $\begin{array}{c}\text { Kabul Edilebilir } \\
\text { Risk Sayısı }\end{array}$ \\
\hline Elektrik & 0 & 1 & 0 \\
Fiziksel (Aydınlatma, sıcaklık vs.) & 0 & 5 & 1 \\
Kimyasal & 3 & 1 & 0 \\
Makine ve ekipman & 1 & 1 & $\mathbf{6}$ \\
\hline
\end{tabular}

Yapılan risk analizi çalışmasının sonucu tehlike kaynaklarına göre risk dağılımı Tablo 8' de verilmiştir. Tablo 8' e göre, toplam risk sayısı en fazla olan tehlike kaynağı "Fiziksel" dir. Bunu "Kimyasal" ve "Makine ve ekipman" takip etmektedir. "Fiziksel" tehlikesinin toplam risk sayısı olarak ilk sırada olmasının nedeni ilgili alanlardaki dağınık kablolar, kapı eşiğinin yüksek olması, uzatma kablolarının bulunması, girişteki mazgal boşluklarıdır. Ayrıca düşme, takılma sonucu ölümlü ve ciddi yaralanmalı bir sonuç olmasa da yaralanmalı bir sonuçla karşılaşılmıştır.

Kabul edilemez (kırmızı) risk toplam sayıları değerlendirildiğinde en fazla risk "Kimyasal” tehlike kaynağında belirlenmiştir. "Kimyasal", SEM laboratuvarında gaz tüplerinin sabitlenmemesi, yanıcı ve patlayıcı kimyasal kullanımı ve bu kimyasalların yanlış konumlandırılması nedenlerinden ötürü ilk sırada yer almıştır.

Kabul edilebilir risk yalnızca "Fiziksel" tehlike kaynağında belirlenmiştir. Asbest uygulama merkezinde termal konfor şartlarında problem olmasına rağmen bu ciddi sağlık sorunu oluşturmamaktadır.

\section{SONUÇLAR}

Çalışmada, L-tipi risk matris yöntemi ile bir kamu kurumunun iki farklı bölümünde(asbest uygulama ve SEM laboratuvarı) risk analizi gerçekleştirilmiştir. Ayrıca, ulusal mevzuat dikkate alınarak mevcut riskler için düzeltici, önleyici tavsiyelerde bulunulmuştur. Risk analizi sonucunda elde edilen risk sayıları ve seviyeleri incelendiğinde, risk sayısı az tespit edilmesine rağmen kabul edilemez risk puanı yüksek (örn. 16 ve 25 puan) olduğu için ilgili bölümlerin riskli olduğu söylenebilir. Bu nedenle kabul edilemez riskler öncelikli olarak bertaraf edilmeli, azaltılmalı veya önlenmelidir. Gerçekleştirilen risk analizi sonuçlarına göre toplam 13 riskin 8'i dikkate değer risk olarak tespit edilmiştir. Dikkate değer riskler tehlike kaynağına göre incelendiğinde en fazla riskin "Fiziksel" kaynaklarda olduğu belirlenmiştir. Dikkate değer risklerin, planlanarak giderilmesi gerekmektedir. Tespit edilen toplam 13 riskin sadece 1’i $(\% 7,6)$ kabul edilebilir risktir. Bu sonuca göre çalışma yapılan bölümlerde risk seviyesinin yüksek olduğu bir kez daha söylenebilir. Çalışanların sağlıklı ve güvenli bir ortamda çalışmaları, kendilerine ve yönetime olan güveni arttırmakta ve iş verimini olumlu yönde etkilemektedir. Çalışanlara İSG hakkında eğitimler verilmeli ve çalışanların riskler 
hakkında bilgi sahibi olmaları sağlanmalıdır. Tehlikeli sınıfta yer almayan bir işyerinde gerçekleştirilen bu risk analizi uygulaması, kabul edilemez risklerin belirlenebileceğini göstermiştir. Tüm işyerlerinde en kötü durum senaryosuna göre etkin risk azaltma planlarının hazırlanması gereği bir kez daha görülmüştür.

YAZAR KATKILARI: Araştırma fikrinin oluşturulması, tasarımı, veri toplanması ŞÜ; analiz, yorum ve makalenin raporlanması ise SÇ tarafından yapılmıştır.

ÇIKAR ÇATIşMaSı: Yazarların herhangi bir çıkar çatışması bulunmamaktadır. Bu çalışmada araştırma ve yayın etiği gereklerine uyulmuştur.

Finansal Destek: Bu çalı̧̧mada herhangi bir kişi, kurum veya kuruluştan finansal destek alınmamıştır.

Етік Коміте Onayı: İnsan örneği veya deneysel çalışma içermediğinden etik kurulu oluru gerekmemiştir.

\section{KAYNAKÇA}

[1] 6331 Sayılı İş Sağlığı ve Güvenliği Kanunu Resmî Gazete Tarihi: 30.06.2012 Resmî Gazete Sayısı: 28339.

[2] İşyerlerinde Acil Durumlar Hakkında Yönetmelik Resmî Gazete Tarihi: 18.06.2013 Resmî Gazete Sayıs1: 28681.

[3] Özkılıç, Ö. (2005). İş Sağlığı ve Güvenliği Yönetim Sistemleri ve Risk Değerlendirme Metodolojileri. TİSK Yayınları, Ankara.

[4] Ersoy, S. Çelenk Kaya, E. (2019). Bir Kamu Üniversitesi Gıda Mühendisliği Laboratuvarları Risk Analiz Uygulaması. Gümüşhane Üniversitesi Sağlık Bilimleri Dergisi, 8 (4), 411-423.

[5] Selçuk, S, Selim, H. (2018). Mücevherat Sektöründe Kullanılan İş Sağlığı ve Güvenliği Risk Analiz Yöntemlerinden L Tipi Matris Yöntemi. İstanbul Ticaret Üniversitesi Teknoloji ve Uygulamalı Bilimler Dergisi, 1 (1), 21-27.

[6] Şafak, R. Şensöğüt, C., Kasap, Y. (2018). Açık Ocak İşletmelerinde İş Güvenliği Uygulaması: Örnek Ocak Çalışması. Bilimsel Madencilik Dergisi. 99-108. https://doi.org/10.30797/madencilik. 493320
[7] Aygül, A. K. E. R. (2020). Metal Sektöründe 5x5 Matris ve Fine-Kinney Yöntemi ile Risk Değerlendirmesi. Karaelmas İş Sağlı̆̆ ve Güvenliği Dergisi, 4(1), 65-75. https://doi.org/10.33720/kisgd.630799

[8] Kabakulak, T. (2020). Bir Tekstil İşletmesinde Risk Değerlendirme Uygulaması: 5x5 Matris ve HAZOP, Karaelmas İş Sağlığı ve Güvenliği Dergisi, 3, 2, 97111. https://doi.org/10.33720/kisgd.581677

[9] Erten, B, Utlu, Z. (2017). İlaç lojistik sektöründe risk analizi yapilarak 5x5 Matris, Fine Kinney ve FMEA yöntemleri ile risk değerlendirmelerinin karşılaştırılması: bir firma örneği. Anadolu Bil Meslek Yüksekokulu Dergisi, 12 (48), 1-14.

[10] Şimşek, S, Ağseren, S, Şimşek, H. (2020). İş Sağlığı ve İş Güvenliği Uygulamalarında Sensör Kullanımının İncelenmesi. İstanbul Aydın Üniversitesi Dergisi, $12 \quad(1), \quad 41-53 . \quad 10.17932 /$ IAU.IAUD.m.13091352.2020.1/45.41-53

[11] Yıldız, Z, Taşyürek, O. (2020). Oto Tamirhanelerdeki Risklerin Değerlendirmesi, Engineering Sciences, 15 (3), 124-138. http://dx.doi.org/10.12739/ NWSA.2020.15.3.1A0456

[12] Usanmaz, D, Köse, E. (2020). Kimyasal Araştırma Laboratuvarı Risk Değerlendirmesi İçin İki Farklı Metodun İstatistiksel Analizi. International Journal of Engineering Research and Development, 12 (2), 337348. https://doi.org/10.29137/umagd.606402

[13] Yap1 İşlerinde İş Sağlığı ve Güvenliği Yönetmeliği Resmî Gazete Tarihi: 05.10.2013 Resmî Gazete Sayıs1: 28786.

[14] İşyeri Bina ve Eklentilerinde Alınacak Sağlık ve Güvenlik Önlemlerine İlişkin Yönetmelik Resmî Gazete Tarihi: 17.07.2013 Resmî Gazete Sayısı: 28710.

[15] Elektrik İç Tesisleri Yönetmeliği Resmî Gazete Tarihi: 04.11.1984 Resmî Gazete Sayısı: 18565.

[16] Binaların Yangından Korunması Hakkında Yönetmelik Resmî Gazete Tarihi: 19.12.2007 Resmî Gazete Sayısı: 26735.

[17] Asbestle Çalışmalarda Sağlık ve Güvenlik Önlemleri Hakkında Yönetmelik Resmî Gazete Tarihi: 25.01.2013 Resmî Gazete Sayısı: 28539.

[18] Çalışanların Patlayıcı Ortamların Tehlikelerinden Korunması Hakkında Yönetmelik Resmî Gazete Tarihi: 30.04.2013 Resmî Gazete Sayısı: 28633.

[19] TS ISO $11625 \mathrm{Gaz}$ Tüpleri - Emniyetli Taşıma ve Kullanma, Madde 8.2.7.

[20] Kimyasal Maddelerle Çalışmalarda Sağlık ve Güvenlik Önlemleri Hakkında Yönetmelik Resmî Gazete Tarihi: 12.08.2013 Resmî Gazete Sayısı: 28733. 